\title{
Erratum to: Reexcision of Soft Tissue Sarcoma: Sufficient Local Control but Increased Rate of Metastasis
}

\author{
A. Rehders • N. H. Stoecklein - C. Poremba • \\ A. Alexander $\cdot$ W. T. Knoefel $\cdot$ M. Peiper
}

Published online: 5 June 2010

(C) Société Internationale de Chirurgie 2010

Erratum to: World J Surg (2009) 33(12):2599-2605

DOI 10.1007/s00268-009-0262-5

The references to "our institution" in both the Abstract and Methods sections of the original paper may be misleading to the reader as the authors' intent was to refer to both
Heinrich-Heine-University Düsseldorf and the University of Hamburg.

All surgeons that collected patients and data, analyzed data, performed follow up, or wrote the original paper moved from the University of Hamburg to Heinrich-HeineUniversity Düsseldorf in 2003.

The online version of the original article can be found under doi:10.1007/s00268-009-0262-5.

\footnotetext{
A. Rehders $(\bowtie) \cdot$ N. H. Stoecklein · A. Alexander .

W. T. Knoefel - M. Peiper

Klinik für Allgemein- und Viszeral- und Kinderchirurgie,

Universitätsklinikum Düsseldorf, Heinrich-Heine-Universität,

Moorenstrasse 5, 40225 Düsseldorf, Germany

e-mail: rehders@med.uni-duesseldorf.de

C. Poremba

Institute of Pathology, Heinrich Heine University, Düsseldorf,

Germany
} 